\title{
Lumen
}

Selected Proceedings from the Canadian Society for Eighteenth-Century Studies

\section{Le tableau libertin ou l'amoral de la peinture}

\section{François Moureau}

Volume 12, 1993

URI : https://id.erudit.org/iderudit/1012582ar

DOI : https://doi.org/10.7202/1012582ar

Aller au sommaire du numéro

Éditeur(s)

Canadian Society for Eighteenth-Century Studies / Société canadienne d'étude du dix-huitième siècle

ISSN

1209-3696 (imprimé)

1927-8284 (numérique)

Découvrir la revue

Citer cet article

Moureau, F. (1993). Le tableau libertin ou l'amoral de la peinture. Lumen, 12,

89-112. https://doi.org/10.7202/1012582ar

Copyright (C Canadian Society for Eighteenth-Century Studies / Sociéte canadienne d'étude du dix-huitième siècle, 1993
Ce document est protégé par la loi sur le droit d'auteur. L'utilisation des services d'Érudit (y compris la reproduction) est assujettie à sa politique d'utilisation que vous pouvez consulter en ligne.

https://apropos.erudit.org/fr/usagers/politique-dutilisation/ 


\section{Le tableau libertin ou l'amoral de la peinture}

Puisqu'il sera à l'occasion question de Diderot dans ce texte, on pourrait l'inaugurer en plaçant en épigraphe celle qu'il donnait au Supplément au voyage de Bougainville: 'Sur l'inconvénient d'attacher des idées morales à certaines actions physiques qui n'en comportent pas.' Dans une variation autorisée, et même si la peinture est 'cosa mentale,' comme le disait Léonard, ou des 'leurres qui persuadent les yeux,' selon l'heureuse formule de Nicolas Poussin, quelques touches de couleur sur de la toile préparée ne produisent certainement pas un discours articulé comparable à celui de la littérature. Le geste du peintre a ce privilège intéressant d'être fondamentalement amoral. Qui ne connaîtrait la vie parisienne 'fin de siècle' pourrait imaginer que les personnes du sexe représentées par Toulouse-Lautrec dans un intérieur d'apparence bourgeoise ou les demoiselles que Renoir peint dans les guinguettes des bords de Marne sont des 'jeunes filles en fleur' et non le produit des 'fleurs du mal.' C'est l'interprétation, le regard de l'amateur qui donne son sens moral au tableau, lequel n'en a pas besoin pour exister pleinement.

Nos siècles classiques en étaient parfaitement conscients. Autant la morale tendait à 'surveiller et punir' la littérature, en général, le roman, les spectacles, l'opéra 'et tous ses lieux communs de morale lubrique, ${ }^{\prime 2}$ autant la pratique picturale échappait presque totalement à ces interdits. A la fin du XVIIe siècle, quand Bossuet tonne contre l'immoralité du théâtre, les théoriciens et les historiens de la peinture débattent du dessin et de la couleur, de la 'balance des peintres,' à la rigueur de la vulgarité de l'art flamand et des sujets de 'bamboche,' jamais de cette illusion scandaleuse que génère l'artiste en se faisant le concurrent du Créateur. ${ }^{3}$ Ce qu'on lui reproche sur une scène de théâtre ne franchit pas les portes de l'Académie de Peinture, qui aurait, normalement, à s'occuper de ces atteintes à l'ordre éternel du monde.

Certes, la théorie classique de la mimésis-'Il n'est point de serpent, ni de monstre affreux / Qui, par l'art imité, ne puisse plaire aux yeux ${ }^{\prime 4}$ autorise des entorses utiles à la représentation des choses. Les passions, dont Charles Le Brun catalogue à l'Académie les variétés et l'expression, ${ }^{5}$ font le quotidien de l'art et de l'homme après la chute. Les gens de 


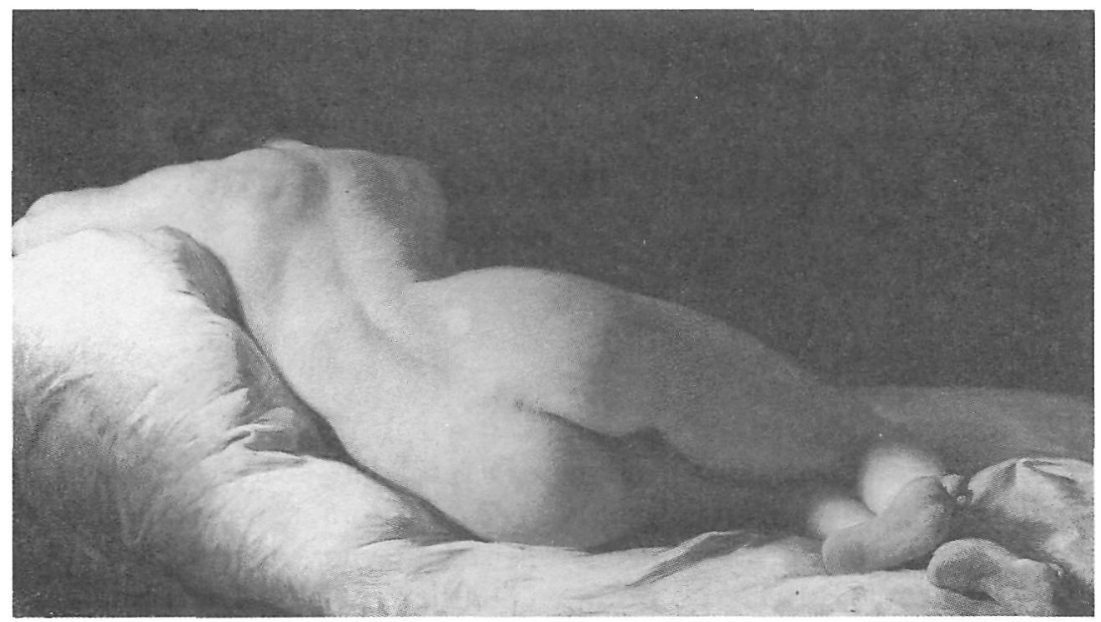

Fig. 1 SUBLEYRAS: Etude Académique de Femme vue de dos.

Rome - Palais BARBERINI.

théâtre, les romanciers, les moralistes, malgré des tentatives émouvantes de tragédies bibliques et d'épopées saintes, se meuvent dans l'univers de la faute morale et du déni des leçons chrétiennes. Le beau prétexte de la catharsis encourage les artistes, sans légitimer complètement cette attirance équivoque pour le péché humain.

La peinture semble, quant à elle, affranchie de ces arguties déplaisantes. Bien plus que d'Apelle, mythe invisible de la peinture antique, elle tire son origine d'un saint Luc peignant le portrait de la Vierge: ${ }^{6}$ celui-ci deviendra le patron tutélaire des Académies professionnelles. Les églises et les lieux de culte se couvrent de représentations à fresque des mystères du Christianisme. La Contre-Réforme fit de la propagande par l'image un des éléments de la reconquête des esprits. La peinture profane bénéficia de ce courant qu'amplifia un mécénat souvent d'origine ecclésiastique. En France, l'Académie de Peinture fut le lieu suprême de la légitimation de l'art des lignes et des couleurs. La représentation du monde y eut ses catégories et ses classements, selon les valeurs mêmes que le Créateur avait imposées à son propre oeuvre. Au sommet de la hiérarchie des peintres, 'l'histoire' donnait à voir l'homme aux prises avec le sacré dans sa dimension chrétienne ou, par la 'fable' antique, les héros de l'histoire profane. A un rang inférieur, le 'portrait' évoquait la figure divine par l'intermédiaire de ses créatures humaines: ici, sainte Véronique était la rivale de saint Luc. ${ }^{7} \mathrm{Au}$-dessous, le 'paysage' parfois animé d'hommes ou d'animaux rappelait le règne végétal. Au degré inférieur, la 'nature morte'-ou la vie silencieuseparfois chargée d'une forte valeur symbolique suggérant la 'vanité' des 
choses terrestres, faisait souvenir le pécheur, par du gibier mort, des fleurs coupées et des fruits mûrs que la sphère du vivant l'emportait provisoirement sur l'éternel silence du règne minéral. ${ }^{8}$ Représenter l'humanité dans son existence quotidienne était en quelque sorte une prière muette à la divinité: le très dévot et janséniste Chardin ne s'y trompa pas ${ }^{9}$ dans une époque où les valeurs chrétiennes n'irriguaient plus guère ce genre de peindre si prisé autrefois des artistes nés dans les Pays-Bas catholiques ${ }^{10}$ ou dans la sévère Espagne.

C'est pourquoi ce qui scandalisait dans le spectacle du monde, ce que la littérature ne pouvait exposer qu'avec mille précautions faisait partie du légitime domaine de la peinture. Il suffira pour le prouver de prendre un seul exemple, celui de la représentation de la nudité. Certes, il fallut attendre le milieu du XVIIIe siècle pour que le corps féminin entrât dans l'enseignement académique (Pierre Subleyras, Etude académique de femme nue, vue de dos; Rome, Palais Barberini, fig. 1) ${ }^{11}$ mais le corps dénudé sous ses diverses formes avait une double justification: la statuaire antique, modèle de substitution à une peinture presque inconnue avant les découvertes d'Herculanum, et surtout la tradition chrétienne. D'Adam et Eve à la Vierge dégrafée pour l'Enfant Jésus, lui même corps offert sur la croix, puis aux saintes martyres allant au supplice dans un divin négligé et à Marie-Madeleine, succès européen insurpassable au XVIle siècle, dont le laisser-aller mystique de sa retraite à la Sainte-Baume marqua plus d'un adolescent, la peinture des premiers siècles de l'ère moderne n'est pas avare en 'nudités de gorge' qu'un docteur en théologie comme Jacques Boileau, frère du satirique, condamne en $1675^{12}$ chez ses contemporaines sans les apercevoir sur les murs des églises. Dans le domaine profane, d'opulentes nudités ornent la proue des navires du Roi; des allégories deshabillées peuplent, mêlées aux princes et aux évêques, les campagnes picturales menées à Versailles et les cartons destinés aux tapisseries royales. Le Brun dessine avec une sensualité, que l'on ne retrouve guère dans ses tableaux, des corps féminins qu'il transforme en nymphes ou en naïades sur la toile peinte. ${ }^{13}$ Le mot de Tartuffe à Dorine-'Cachez ce sein que je ne saurais voir'-n'aurait décidément pas sa place dans le système d'allégorisation de la monarchie de droit divin.

Cette singulière cécité morale sur ce qui est, pour tout bon catholique, la chair et l'image de l'homme déchu engendre une pratique schizophrénique de l'image: le réel scandalise; l'art élève l'esprit et éduque la sensibilité. Cela suffirait-il à expliquer l'émergence d'une peinture que, faute de mieux, on pourrait nommer 'libertine'? Non, car il y a des raisons sociologiques dont l'importance est, à mon sens, tout à fait déterminante. J'en ai fait naguère l'étude à propos de l'oeuvre de Watteau. ${ }^{14} \mathrm{~A}$ côté du 'collectionnisme' classique qui était le fait d'institutions 


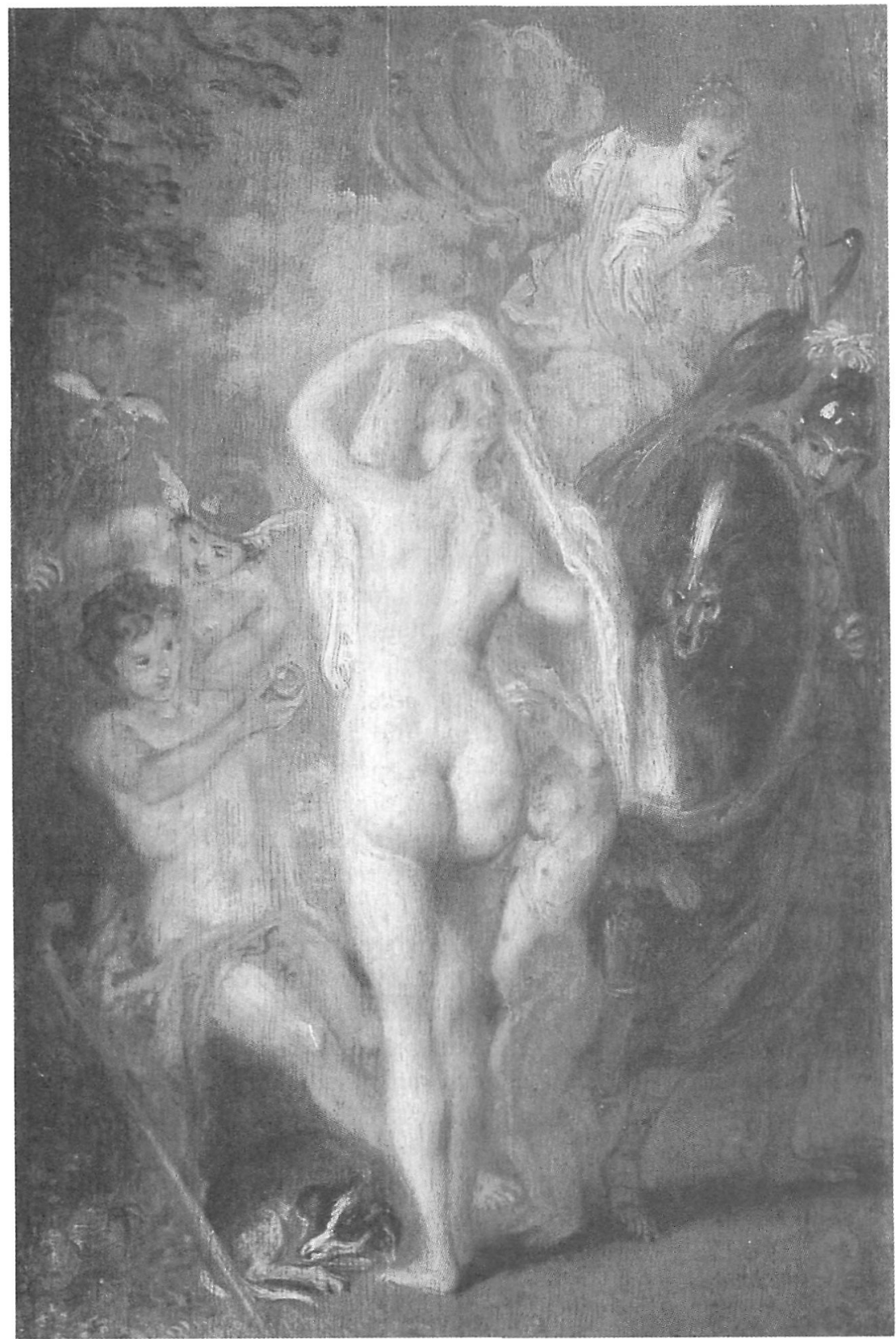

Fig. 2 Le Jugement de Pâris. Paris Louvre (C.-R. 210) (C) «Cliché Musées nationaux». 
ou de personnes publiques-princes, gens d'Eglise, etc. ${ }^{15}$ - se développe en France, dans la seconde moitié du XVIIe siècle, une nouvelle catégorie d'amateurs, ces 'curieux' des deux sexes, ${ }^{16}$ pour qui la peinture est un signe de reconnaissance sociale. Le tableau n'est plus destiné à magnifier la grandeur divine ou le pouvoir du prince, il sert à décorer l'intérieur bourgeois ou artistocratique, à ranger son propriétaire dans une hiérarchie 'qui n'est plus de naissance ou de fonction, mais d'apparence et qu'on appelle 'vivre noblement.' Ce monde de l'argent que décrit un moraliste comme La Bruyère ${ }^{17}$ dont le théâtre comique des successeurs de Molière est envahi, ces 'Turcaret' vont contribuer à renouveler l'art de vivre.

L'aristocrate séjournait dans son château de province ou à la Cour; le nouveau riche s'installe à Paris. Il recrute architectes et décorateurs. Il va tenter de combiner ce qu'un mot venu d'Angleterre nomme le 'confort' avec un certain 'décorum' qui le fait entrer par la petite porte-celle du paraître—dans l'univers mythique de l'ancienne noblesse. Il achève la transformation de l'habitat médiéval et renaissant: on invente pour lui 'l'hôtel particulier' qui, pendant deux siècles, sera le lieu privilégié de la bonne société. Aux pièces de réception centrales sont adjoints des appartements en retour d'ailes où la sphère du privé domine. La notion même d'appartement, de pièces d'habitation spécialisées, remplace celle de 'salles' à affectations multiples qu' on rencontre encore, par exemple, dans les représentations gravées d'Abraham Bosse au milieu du XVIIe siècle. A architecture d'intérieur nouvelle, art nouveau. $S i$ les grandes machines 'historiques' peuvent se concevoir dans les pièces de réception, la dimension intime des pièces $d$ 'habitation exige une peinture $d^{\prime}$ 'un format plus réduit et d'un style moins pompeux pour s'adapter à l'usage privé qu'on fait de ces lieux.

L'oeuvre de Watteau est-à quelques notables exceptions près-composé de petits formats, même quand il s'agit de présenter les sujets classiques de la peinture d'histoire. Le Jugement de Pâris du Louvre (M. I. 1126) (fig. 2), qui se mesure avec une partie non négligeable des Ecoles italienne et française, est un tableau minuscule $(47 \times 30,7 \mathrm{~cm})$, dont le contenu idéologique est lui aussi adapté aux nouveaux amateurs. ${ }^{18}$ Ceux-ci se trouvent confrontés à deux tentations contradictoires: 'vivre noblement,' c'est respecter les valeurs traditionnelles de l'aristocratie, dont fait partie la culture historique et antique, mais, d'un autre côté, il s'agit d'adapter le style de vie contemporain aux valeurs nouvelles de 'modernité' et de 'mode' évolutive ou changeante. A une société humaniste et immuable dans ses principes, monarchique et chrétienne dans sa morale sociale, se substitue un univers où règnent le regard critique et le primat de la sensibilité individuelle. La quête du bonheur personnel, la leçon des sens préférée à celle de la règle imposée de l'extérieur, 


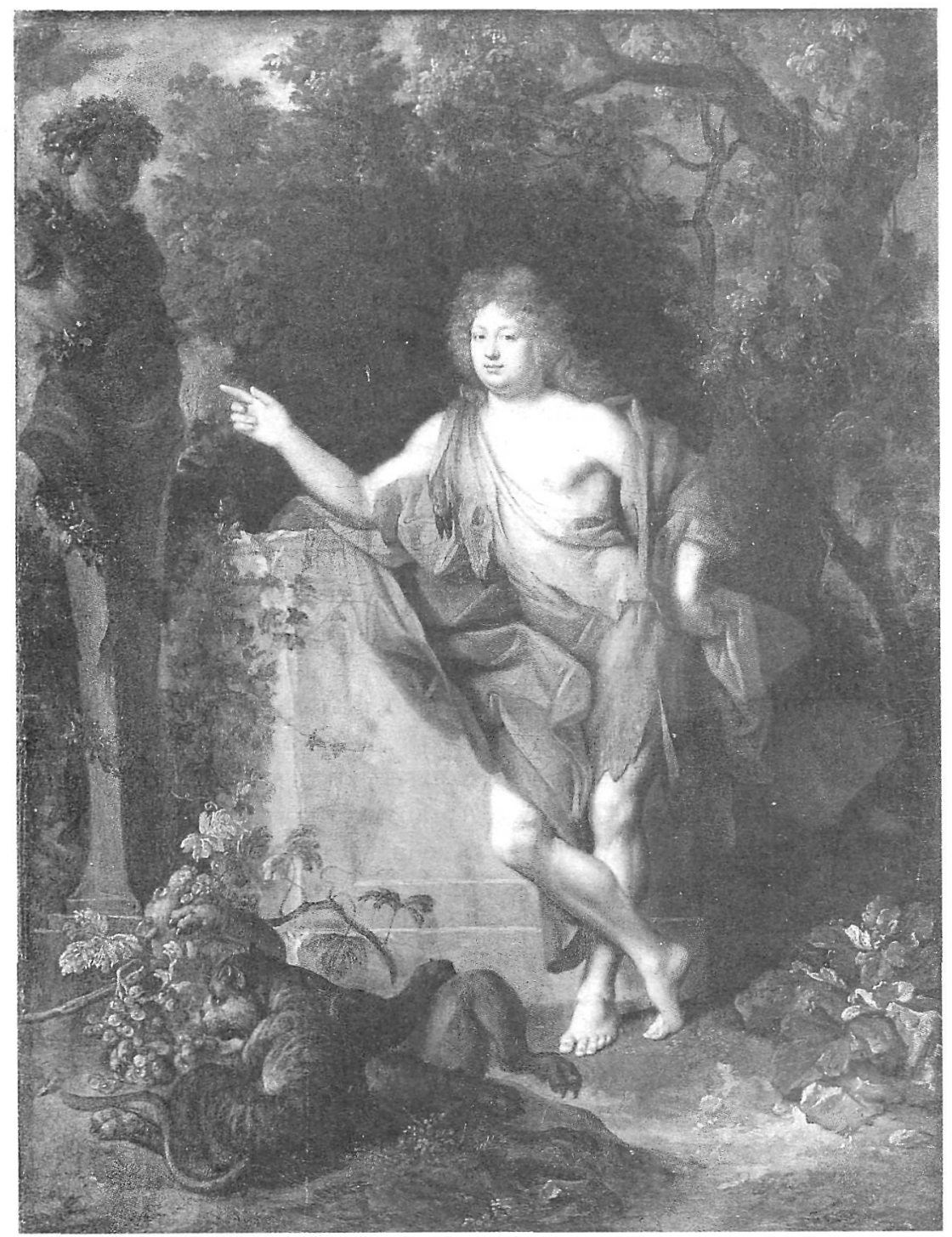

Fig. 3 Portrait allégorique dit: Le Régent en Dieu Pan. Louvre, inv. R. F. 2155

tout cela annonce quelques thèmes centraux de la philosophie des Lumières. La peinture y participe à sa manière.

Les curieux et amateurs n'ont certainement pas une conscience claire qu'ils contribuent à la naissance d'un monde nouveau et à l'enterrement $\mathrm{d}^{\prime}$ 'un autre, mais ils savent très exactement ce qu'ils veulent sur les murs de leurs demeures: une peinture qui soit digne du grand genre et qui 
témoigne du temps présent. Dans Le Jugement de Pâris, inspiré pour certains détails de Rubens, la composition monumentale est au service d'une relecture de l'histoire homérique qui évoque le parodie contemporaine faite de L'Iliade par Marivaux-L'Homère travesti de 1716-dans le contexte de la seconde Querelle des Anciens et des Modernes où Homère tient le role d'accusé-prétexte. Ce n'est plus Athéna, ici simple sorcière dépouillée de tout attribut divin et de sa symbolique philosophique, mais Hélène qui représente, par cette vue de dos centrée et ondulante, la libération de la sensualité face au monde ancien effrayé et déjà hors du réel. Mercure est là, annonciateur des temps nouveaux, non plus d'un Age d'Or mythique, mais de celui de l'argent et du plaisir. Le jeu des couleurs-rose chair contre vert sombre-fait de ce tableau un manifeste de la nouvelle école aussi transparent que l'illustre Pèlerinage à l'île de Cythère peint à la même époque.

Si la personnalité complexe de Watteau n'est pas à rattacher entièrement au milieu 'moderne' qu'il dépasse largement, ${ }^{19}$ ni même au milieu intellectuel qui se reconnaît dans le libertinage ${ }^{20}$ la clientèle d'amateurs qui le soutient appartient en majorité aux catégories citées plus haut: Pierre Crozat 'le pauvre,' banquier fastueux ${ }^{21}$ chez qui Watteau a le vivre et le couvert, la comtesse de Verrue, dite, à bon droit, 'Dame de Volupté,' Jean Leriget de la Faye, spéculateur averti, ${ }^{22}$ ou le manufacturier Jean de Jullienne, ${ }^{23}$ qui diffusa l'oeuvre de Watteau en le faisant graver. Le Régent dessine lui-même des illustrations de pastorale 'moderne' pour Daphnis et Chloé de Longus (1714-1719) et achète deux oeuvres au peintre de Valenciennes. ${ }^{24}$ Libertin et homme de progrès, Philippe d'Orléans s'était empressé, dès la mort de Louis XIV, de faire tout le contraire de son oncle et de soutenir ce qu'il avait condamné. Il installa Fontenelle, symbole de l'esprit nouveau et pape de la 'modernité,' dans sa propre résidence du Palais-Royal. ${ }^{25}$ On le peint, presque nu, dans une toile où il pose en Bacchus ${ }^{26}$ à côté $\mathrm{d}^{\prime}$ un terme représentant Silène (fig. 3). Cette scandaleuse nudité parodie et inverse le sens des classiques portraits à la romaine dont les princes avaient coutume d'orner leurs salles de réception: la dérision du grand genre, l'insolente provocation du modèle donnent à cette oeuvre singulière un cachet tout à fait exceptionnel dans la production picturale française du début du XVIIIe siècle. ${ }^{27}$ On retrouve les mêmes dieux-termes dans nombre de scènes de parc peints par Watteau, ${ }^{28}$ il s'agit d'un signe, sinon d'une signature.

La notion de 'fête galante' créée pour la réception de Watteau à l'Académie de Peinture en 1717 est autre chose, en effet, que la simple constatation d'un voie picturale neuve. ${ }^{29}$ Depuis le début du règne de Louis XIV, la hiérarchie des arts, dont nous parlions plus haut, s'était imposée à tous les artistes; elle fut de nouveau leur règle après 1730 . Le Pèlerinage à l'île de Cythère (Louvre, inv. 8325), son tableau de réception 
que Watteau mit plus de cinq ans à fournir à ses confrères, n'est pas seulement une grande machine complexe imitant la peinture $d^{\prime}$ 'histoire ${ }^{30}$ par son format $(194 \times 129 \mathrm{~cm})$, la variété de ses personnages et l'évocation directe de Vénus par le terme situé à droite, c'est un tableau 'moderne' à plusieurs titres: au plus superficiel d'abord, dans les costumes; ensuite, dans la représentation, non d'un héroïsme antique magnifié ou même de quelque Silène, allégorie de toutes les ivresses, mais de la libération des âmes et des corps en dehors de toute référence sociale ou éthique. La 'fête galante' marque la naissance du nouvel Age d'Or, dont les poètes officiels du temps, de Fontenelle à La Motte, ${ }^{31}$ ont déjà fait hommage au Régent. Si le Pèlerinage est en ce sens un tableau politique, ce serait le réduire de n'y voir que cela. Hors du temps-les costumes contemporains sont agrémentés de fantaisies archaïsantes; arrivée ou départ de l'Ile de Cythère, on ne sait-ce tableau est la plus belle illustration de ce 'libertinage d'esprit' que son ami Gersaint attribuait au peintre. ${ }^{32}$ Il était loin des bacchanales où il s'était sans doute exercé dans les premiers ateliers qu'il avait fréquentés: Claude Gillot ${ }^{33}$ ou Jean-Jacques Spoède. ${ }^{34}$ La pesanteur obsédante de ces scènes dont la sensualité primitive ne l'avait retenu qu'un moment avait totalement disparu des larges paysages animés où le corps jouissait de l'esprit.

L'art de Watteau, plus calculé qu'il n'y paraît, est la forme suprême d'une esthétique qui va dégénérer rapidement avec ses épigones et l'image dépréciée qui va en être donnée. On évoque à son propos le peintre flamand, spécialiste de 'grotesques' à la Téniers, ${ }^{35}$ la 'bamboche,' les scènes de genre, une frivolité indifférente à la réalité. La mort du Régent, trois ans après celle du peintre, va permettre à la critique de relever la tête. On parlait déjà de peinture facile, à la mode, de coloris fardé qui dissimulait la faiblesse du dessin, de 'papillotage,' de figures de 'poupées.' Limojon de Saint-Didier condamnait dès 1716 ces 'peintres [qui] affectent de s'éloigner autant qu'ils se trouvent éloignés de l'Antique. ${ }^{36}$ Cette décennie de liberté morale aura été aussi une période de cynisme social et le règne des spéculations financières induites par le Système de Law. Les amateurs de peinture étaient dans leur existence quotidienne des hommes d'argent; bien peu pouvaient se targuer, tout en vivant 'noblement,' d'une aristocratique indifférence aux biens de ce monde. On enveloppa dans une même condamnation morale les amateurs et la peinture qu'ils avaient suscitée. La crise de la hiérarchie des genres très sensible dans les décennies 1710-1730, où fleurit une peinture hors normes, va connaître dès le début des années 1740 une embellie bientôt officiellemnt soutenue par le marquis de Marigny, frère de Madame de Pompadour et Surintendant des Bâtiments, qui, après un séjour en Italie et la découverte d'Herculanum, va permettre, par le 
retour à l'Antique, d'envisager une nouvelle légitimité au grand genre et à la peinture $\mathrm{d}^{\prime}$ histoire. ${ }^{37}$

C'est pourquoi il faut étudier le courant libertin en peinture dans les diverses formes qu'il prit au cours du XVIIIe siècle français. ${ }^{38} \mathrm{~A}$ côté $\mathrm{d}^{\prime}$ une peinture de cabinet audacieuse dans sa représentation et dans ses thèmes, il ne faut pas oublier une tradition qui utilise le grand genre et les formes académiques pour les détourner au profit d'une idéologie 'régénérée,' comme l'on dira sous la Révolution.

La peinture clairement libertine est celle qui offre le moins de mystère au regard du spectateur. Elle utilise des ressorts assimilables à ceux de la littérature de 'curiosa' récemment étudiée par Jean Marie Goulemot: ${ }^{39}$ il s'agit de ressusciter l'instinct du voyeur et de le faire participer, comme d'autres regards présents à l'occasion sur la toile, à la délectation de la chair offerte dans ses rondeurs et ses couleurs tendres. Les Petites Curieuses de Fragonard (Paris, Musée du Louvre; Wildenstein-Mandel 297) donnent la main à L'Indiscret de Watteau (Rotterdam, Musée Boymans-van Beuningen; C.-R. 140); ils fixent le spectateur en même temps que leur proie, et c'est dans la 'réversibilité' du regard que se situe le point de fusion du réel et de la toile. Le voyeurisme est la limite la plus apparente de cet art de l'excitation primitive et de l'allusion directe.

Watteau pratiqua cet art dont on se délectait, solitaire ou avec quelques complices choisis, dans l'intérieur de cabinets clos au reste de la société civile: ces toiles n'ornent jamais les murs offerts au tout venant des résidences de l'aristocratie financière; on les rencontre, dit un moraliste du temps, dans des 'réduits infâmes, où des peintures lascives donnent une si naïve et si horrible copie de la corruption du coeur de celui à qui elles appartiennent. ${ }^{40}$

Le premier biographe de Watteau, Antoine de la Roque, parle de son goût pour la 'carnation [...] animée et douillette. ${ }^{\text {,1 }}$ Caylus, son ami des dernières années, évoque ailleurs les 'retraites' 'qui ne servaient qu'à poser le modèle'; il ajoute:

n'ayant aucune connaissance de l'anatomie, et n'ayant presque jamais dessiné le nu, il ne savait ni le lire, ni l'exprimer; au point même que l'ensemble d'une académie lui coûtait et lui déplaisait par conséquent. Les corps de femmes exigeant moins d'articulations lui étaient un peu plus faciles. ${ }^{42}$

Si l'œuvre libertine de Watteau a disparu pour partie, il faut en chercher le responsable dans le peintre lui-même. Caylus écrit assez curieusement: 


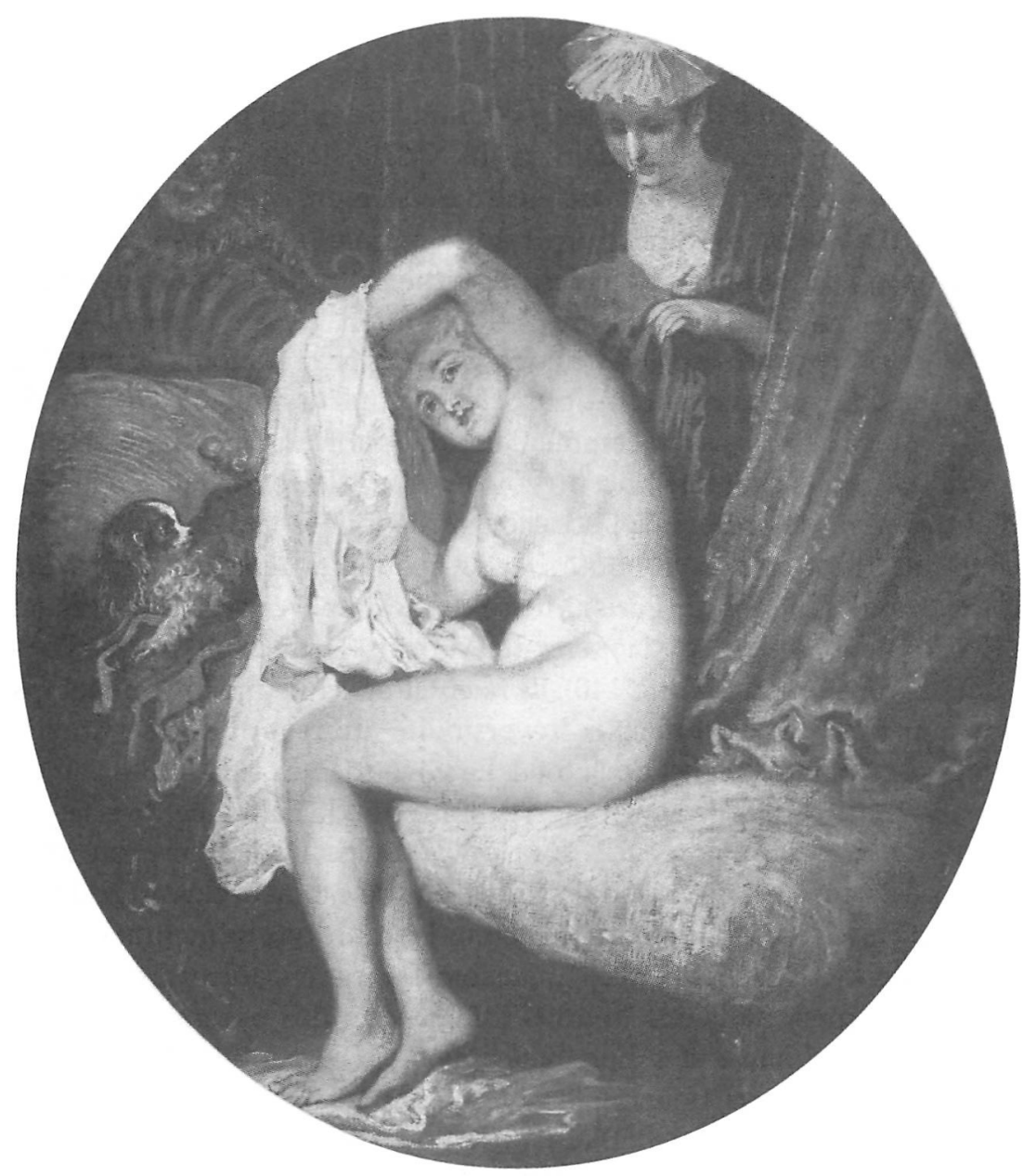

Fig. 4 La toilette. Londres, Wallace Collection (C.-R. 175)

aucun vice ne le dominait et il n'a jamais fait aucun ouvrage obscène. Il poussa même la délicatesse jusqu'à désirer, quelques jours avant sa mort, de ravoir quelques morceaux qu'il ne croyait pas assez éloignés de ce genre, pour avoir la satisfaction de les brûler: ce qu'il fit. ${ }^{43}$

Son œuvre dessiné est en effet largement mieux représenté sur ce thème que l'oeuvre peint; on connaît des séries de nus, généralement allongés sur un lit de repos et dévoilant, de face ou d'un profil coquin souvent agrémenté d'une chemise qu'on enlève, des anatomies très réalistes 
(P.-M. 519, 522). Le même modèle, une jeune fille aux rondeurs flamandes, a servi pour la plupart de ces dessins faits 'ad vivum,' 'sur le vif' (P.-M. 524-528). Une très académique 'esquisse de nu féminin' (P.-M. 530) rappelle les statues dénudées que l'on rencontre dans des nombreuses toiles du peintre.

En effet, selon son habitude, Watteau a tiré de ses carnets d'esquisses des compositions peintes complexes. Cela va d'une jolie et anonyme baigneuse qui s'essuie (dessin: Vienne, Albertina, P.-M. 854)-intitulée au moment de la gravure:" 'Diane au bain' (Paris, Louvre, C.-R. 113)-à des sujets nettement moins académiques comme La Toilette (Londres, Wallace Collection, C.-R. 175) (fig. 4) ou La Toilette intime (France, coll. part., C.-R. 157). Dans le premier exemple, le modèle qui enlève sa chemise sur le lit en fixant le spectateur enferme celui-ci dans un rôle de voyeur obscène que tend encore à renforcer la peu équivoque invite de la jeune fille. Derrière elle, la servante est l'emblème traditionnel de la luxure dans la littérature et la peinture galantes: 'meretrix' ou 'Célestine,' elle facilite le 'commerce' amoureux. On la retrouve dans $\mathrm{La}$ Toilette intime, où sa fonction a évolué, passant du statut d'observateur et d'adjuvant à celui d'acteur. Cette toile très élégante par son rendu et ses couleurs bouillonnantes dépasse largement l'anecdote scabreuse qu'elle représente. Mais il s'agit typiquement d'un tableau de cabinet. L'architecture de l'oeuvre est centrée sur le sexe de la jeune fille vers lequel convergent son propre regard et celui de la servante. Ce moment lustral en évoque d'autres moins purs que la toile suggère dans un passé récent. Les deux femmes sont seules, habitées d'un silence réfléchi, attentives à leur acte de purification dont tout autre spectateur est banni. Cet instant de femmes rend encore plus gênant le regard qui viole leur intimité en se fixant sur la toile. Watteau a réalisé là un chef-d'oeuvre de scandale allusif et d'érotisme 'philosophique.' La réussite est d'autant plus absolue que le sujet était techniquement difficile: la frontalité des personnages, leur immobilité, le rosé de la carnation sur le laiteux moussant du lit, le fond uni rendaient l'entreprise délicate et le résultat vraisemblable d'une pâle vulgarité. Le génie de Watteau a opéré sur un sujet de commande. Car on ne peut imaginer que cet artiste qu'on décrit 'né timide ${ }^{45}$ ait de lui-même songé à peindre ces scènes.

La médiocrité de La Femme nue et couchée (Los Angeles, Norton Simon Foundation, C.-R. 135)—fragment très repeint certes-montre combien Watteau eut de difficultés à se plier aux caprices de ses commanditaires. L'original perdu avait été peint pour le banquier Crozat; on sait par un dessin conservé (Paris, coll. part. P.-M. 865) que la femme nue vue de face était, avant les repeints et la réduction à droite du panneau, soumise à l'épreuve d'un clystère que lui présentait une servante obligeante. Ce sujet 'nordique' à l'obscénité à peine déguisée donne lieu à des sinuosités 
où se combinent le corps de la femme et les plis du drap. Elle tord la tête pour fixer comme dans La Toilette intime l'objet et sa destination. Tout cela est morne, sans mouvement, comme si l'artiste s'ennuyait à peindre, ce qui est étonnant quand on connaît sa fougue devant la toile dont tous ses amis témoignèrent dans leurs souvenirs. Vendu en 1765 avec la collection Crozat et jamais gravé, le tableau dut être connu auparavant des cercles d'amateurs. Antoine Pesne, Premier peintre de Frédéric II, mais qui avait fait toute son éducation à Paris, en donna vers 1745 une interprétation qui n'améliore pas le résultat (Scène galante. Berlin, Charlottenbourg) ${ }^{46}$ Ce regard torve qui s'adresse au miroir et au voyeur rejoint les pires conventions du genre, de même que le galant qui la manipule et lui donne par sa main gauche la mesure de ses ambitions. L'image du bas du dos fournie par le miroir complète celle qui est donnée de face: totalement offerte, la femme céde son intimité au premier venu, le peintre ou le spectateur.

Le tableau de Pesne se trouvait dans la collection personnelle du roi de Prusse; les toiles libertines de Watteau dans celles de puissants financiers ou de grands aristocrates français et étrangers: ${ }^{47}$ le monde de la peinture de genre galant aggravé n'est pas, de toute évidence, celui qui achète sur le Pont-Notre-Dame la copie des toiles flamandes dont Watteau fit son gagne-pain à son arrivée à Paris. Mais ces collectionneurs ont d'autres qualités; ils possèdent des chefs-d'œuvre de la peinture ancienne qui inspirèrent, on s'en doute, les artistes qu'ils protégeaient. Nous le disions plus haut, il n'y pas de rupture entre la peinture à coloration clairement libertine et une certaine 'grande manière.' Watteau copie Rubens chez Crozat et chez d'autres: ici, c'est Ariane Bacchus et Vénus (Londres, British Museum. P.-M. 263) du cycle de Marie de Médicis; là, une Marche de Silène (Massachussetts, coll. part. P.-M. 259), libre interprétation du Triomphe de Silène de l'Anversois (Londres, National Gallery). On retrouve ces Silènes et ces Bacchus en dieux-termes dans tellement d'oeuvres de Watteau qu'ils en paraissent, on l'a dit, ${ }^{48}$ la signature, comme les statues de femmes nues allongées qui en sont la transcription féminine et allégorique. ${ }^{49}$ Le songe, la sensualité, le vin qui les engendre et les soutient: il y là une bonne part de la philosophie d'une société qui a rompu ses liens avec le christianisme et dont la peinture crée la nouvelle mythologie à partir d'éléments disparates.

Car c'est bien d'un univers culturel original qu'il s'agit. Généralement moins cultivée que les mécènes anciens ou les princes de l'Eglise, la nouvelle aristocratie financière, qui s'allie rapidement à la grande noblesse, 'réargentant' ainsi les vieux écus de la féodalité expirante, suscite un imaginaire à sa mesure. Nous avons expliqué ailleurs le développement des sujets théâtraux chez Watteau et chez ses contemporains par ce phénomène d'innutrition culturelle: Pierrot, Arlequin, Colombine rem- 
placent Apollon, voire Vénus et la Légende dorée. ${ }^{50}$ La multiplication des thèmes littéraires modernes va dans la même direction. Limitons-nous à La Fontaine. Ce n'est pas l'auteur des Fables qui est le mieux représenté dans l'art du XVIIIe siècle, ${ }^{51}$ mais celui des Contes, ces pièces de vers dont la morale est rien moins que convenable et qui font le portrait complaisant d'une humanité asservie à ses passions. Il n'est pas inutile de noter que la grande édition des Contes faite au XVIIIe siècle est dite 'des Fermiers Genéraux, ${ }^{, 52}$ ces financiers qui se chargèrent $d$ 'en réaliser l'impression et la somptueuse illustration. Les contes les plus scabreux donnent lieu à des interprétations picturales, comme si le prestige de leur source autorisait de telles entorses à la morale sociale officielle. 'Les Oies de frère Philippe, nouvelle tirée de Boccace' (Contes, 3e partie) inspirent plusieurs peintres. ${ }^{53}$ Le sujet du conte est assez caractéristique de l'image que le genre donne du sexe faible, puisque le naïf fils de l'ermite prend les premières femmes qu'il rencontre pour des animaux de basse-cour, d'où le titre. C'est dans l'entourage immédiat de Watteau, et sans doute pour les mêmes amateurs, qu'on voit s'en multiplier les évocations: son ami Vleughels, ses disciples Lancret et le jeune Boucher (Besançon Musée des Beaux-Arts), qui cède sa gouache à Jean de Jullienne, le protecteur de Watteau. ${ }^{54}$ Le libertinage du sujet est traité par allusion, car on ne voit guère quel'ermite et son fils devantl'essaim de jeunes demoiselles au brillant plumage. Tout cela est galant, sans être franchement immoral.

Pierre Subleyras, Français établi à Rome, en donne plusieurs versions (Paris, Louvre; Boston, Museum of Fine Arts) qui rentrent dans le cycle des contes de La Fontaine qu'il peint pour des amateurs romains. A la même époque, Nicolas Vleughels, futur directeur de l'Académie de France à Rome, traite lui aussi de ces thèmes internationaux, dont la source première était d'ailleurs italienne. ${ }^{55}$ Chez Subleyras, seul l'arrière-plan littéraire est libertin, sauf dans le nu vu de dos de La Jument du compère Pierre (Saint-Pétersbourg, Musée de l'Ermitage); il s'agit d'un langage codé. ${ }^{56}$ Sur la toile, on ne voit que des formes élégantes, un rendu de couleur raffiné, des scènes d'intérieur intimistes. La Courtisane amoureuse (Paris, Louvre, R.F. 1985-80) montre une jeune femme déchaussant son amant avec des gestes de tendre attention; Le Faucon (Paris, Louvre, inv. 8010) évoque une fin de repas propice aux aveux de sentiments. Rien de cela n'a la brutalité des tableaux de cabinet signalés plus haut. Certains des sujets de Vleughels furent gravés par Nicolas de Larmessin (Hercenberg 132-137), et les tableaux de Subleyras, ou leurs répliques, apparaisssent dans de nombreuses ventes du XVIIIe siècle: celle du duc de Saint-Aignan, ancien ambassadeur à Rome, ou celle de Natoire, directeur de l'Académie de France. Il y a là le témoignage de vrais amateurs en faveur d'une peinture renouvelant l'iconologie traditionnelle. Fragonard, que nous retrouverons dans d'autres entreprises 
plus directement érotisées, traite avec moins de candeur des thèmes lafontainiens, dont une Perrette et le pot au lait, fable à acteurs humains, dont il exprime,sans la moindre retenue, l'équivoque sensuelle (Paris, Musée Cognacq-Jay): l'aspect mousseux du tableau, ces jupes retroussées caressées par la fumée (?) qui s'échappe du pot renversé, donnent de la 'morale' fabuliste une vision qui annonce d'autres tentatives de Fragonard dans le domaine de l'allusion obscène.

L'art de Fragonard qui sait parfaitement envelopper d'un sfumato brumeux, et d'autant plus équivoque, les scènes de commande dont il se fait un ouvrier très consciencieux s'inspire d'une tradition nordique dans la peinture de genre. Les sujets intimistes, ces enfants ébouriffés, ces jeunes filles rêveuses à leur fenêtre font partie de son répertoire. Chez Watteau, la sensualité est directe ou poétisée, de quelque manière, saine; Fragonard est, lui, un pervers lucide, ou qui veut, du moins, s'en donner la réputation. Quand François Boucher peint ses odalisques exposant leurs 'parties ridicules' (Odalisque brune: Paris, Louvre, R. F. 2140; Odalisque blonde: Munich, Alte Pinakothek), ce n'est que jeu un peu poivré, fantaisie libertine au premier degré. On ne sait pas, d'ailleurs, à qui étaient destinées ces représentations présumées de la petite Victoire O'Murphy et de sa soeur Louise, passade royale sans conséquence. Une version de l'Odalisque brune appartint au fermier général Le Riche de la Poupelinière dont l'épouse était connue pour ses frasques: il put s'en venger par ce tableau d'une conquête adolescente, qu'il partageait avec beaucoup d'autres, si l'on en croit la multitude des versions autographes de cette oeuvre. ${ }^{57}$

Sinon chastes, ces portraits demeurent néanmoins élégants. Le magnifique portrait dela maîtresse en titre,Mme dePompadour, a tout du grand style de Cour: vue en pied, la marquise est environnée des meubles et des livres qu'elle aime (Munich, Alte Pinakothek). La Diane au bain de Boucher (Paris, Louvre, inv. 2712) supporte la comparaison avec celle de Watteau: elle a même un rendu porcelainé et doré qui en renforce l'effet poétique. Au contraire, les 'figures de fantaisie ${ }^{58}$ de Fragonard, parmi lesquelles celle du philosophe Diderot-qui n'en dit jamais mot-(Paris, Louvre), témoignent de la virtuosité de l'artiste, mais surtout d'une confusion de plus en plus grande des catégories picturales jusqu'alors respectées. Le portrait de Mlle Guimard, comédienne fort libertine (Paris, Louvre), appartient à ces effigies romanesques d'où tout réalisme est banni. Le vice est apparent sur la toile. Diderot, qui n'aimait guère Boucher, ${ }^{59}$ est encore plus sévère pour ce Fragonard-là qu'il connaît indirectement d'ailleurs, puisque les tableaux les plus audacieux de l'artiste ne sont pas exposés, on s'en doute, aux Salons de l'Académie de peinture dont Diderot rend compte. L'érotisation de la toile est directe, sans autre gaze que le travail de la matière si caractéristique de Fragonard. 
Parallèlement à ses travaux 'académiques,' Fragonard travaille pour certains particuliers à qui il fournit une peinture de délectation obscène au premier degré. Cette pratique libère l'artiste des contraintes de l'institution royale, mais elle l'asservit à la 'mode' et aux volontés de ses commanditaires. Il ne s'en plaignit pas, semble-t-il. Il répète à satiété certains sujets qui ont l'alcôve pour décor: scène à deux ou plaisir solitaire, tout y est. Le couple avant d'engager l'acte ébauche un ballet érotique dont le 'verrou' est la clé (Le Verrou; Paris, Louvre); L'Instant désiré (Suisse, coll. part.) représente l'acte. Fragonard mêle volontiers des enfants, réputés donner une touche $d^{\prime}$ innocence à ces fantaisies libidineuses. Le trio enfantin de L'Enjeu perdu (New York, Metropolitan Museum) ou des Apprêts du repas (Moscou, Musée Pouchkine) découvre l'amour en groupe comme un autre plaisir de la bouche: future 'Célestine,' une petite fille déja avertie aide le jeune garçon à parvenir à ses premières fins. ${ }^{60}$

Mais la meilleure érotisation, celle qui convient le plus au statut de voyeur que l'on nous attribue, est favorisée par les jeux solitaires des jeunes filles. Sans intermédiaire masculin qui gênerait, pour le 'voyeur,' la lecture du tableau, la sexualité de la femme y parait telle que l'homme se l'imagine: torrentielle, animale. Les divertissements érotiques qu'elle s'accorde avec son petit chien de compagnie donnent à ce couple mutuellement fasciné une signification emblématique. ${ }^{61} \mathrm{~A}$ côté du chien, on trouve d'autres représentants de la ménagerie érotique: le chat, ${ }^{62}$ la colombe ${ }^{63}$ ou la marmotte, ${ }^{64}$ voire un putto animé. ${ }^{65}$ Mais, le plus souvent, ce sont des objets variés: gimblettes-il s'agit de gâteaux en forme d'anneaux-, pétards, jets d'eau, brandons allumés, verre d'eau, boudin, qui ont fonction de substitut de l'organe sexuel et de membre postiche du voyeur. ${ }^{66}$ Fragonard réussit le prodige d'être totalement obscène et vulgaire dans un propos que la palette de l'artiste transcende en volutes poétiques. On n'a jamais été aussi près, avant Baudelaire, de représenter les 'fleurs du mal.'

L'art de Fragonard est l'aboutissement d'une tradition de peinture à codage libertin. S'il passe franchement de l'allusion à la représentation directe, on suit aisément dans son oeuvre le cheminement des diverses leçons qu'il a reçues: celle de Boucher d'abord. Des toiles de jeunesse comme la série des panneaux Mortemart (Detroit, Detroit Institute of Arts; W.-M. 34-37) trahissent la grammaire iconologique de Boucher: ce 'moissonneur' tenant d'une main une corbeille de fleurs et de l'autre une colombe fait pendant à la 'vendangeuse' qui prend à pleines mains une grappe de raisins qu'elle va glisser, en détournant le regard, dans son tablier déjà chargé: ces sujets rappellent, jusque dans les couleurs acidulées, la manière du Premier peintre et cette symbolique de l'objet signifiant que l'on retrouve même chez des artistes les moins sensibles à 
l'air libertin du temps, comme Chardin ou Greuze. ${ }^{67}$ Mais Fragonard sait aussi détourner la thématique iconographique de ses contemporains: une scène de drame bourgeois à la Greuze devient dans $L^{\prime}$ Armoire ${ }^{68}$ un thème de vaudeville. Le jeune garçon dissimulant son sexe grâce à son chapeau est extrait d'une armoire où il s'est cachéà l'arrivée des parents de la jeune fille qui pleure davantage d'être découverte qu'une virginité envolée sur le lit défait à droite de la scène.

Séjournant en Italie comme pensionnaire de l'Académie de France, Fragonard a su y copier l'antique dans sa variété thématique. ${ }^{69}$ Au même moment, Winckelmann replaçait l'érotisme de l'art des Anciens dans le grand courant de la philosophie naturaliste ${ }^{70}$ dont, des siècles durant, le Christianisme avait condamné la morale et l'esthétique. Ces 'nymphes et satyres,' qui, chez Watteau, n'étaient que prétextes à académies et à sinuosités picturales, prennent chez Fragonard, dans ces décennies de 'retour à l'Antique,' une coloration idéologique très marquée. L'animalisation de l'homme par le biais du satyre, le triolisme de scènes où la gymnastique sexuelle bannit tout sentiment ${ }^{71} n^{\prime}$ est pas un simple topos archéologique, comme en témoignent les quatre bacchanales gravées dont les modèles antiques ont été largement adaptés par Fragonard. ${ }^{72} \mathrm{La}$ leçon de l'Antiquité classique qui va bientôt submerger et refroidir l'art européen a d'abord ces tentations libertines que l'exhumation d'Herculanum, le 'musée secret' de Naples, les campagnes de gravures d'un jeune Jacques-Louis David et les ouvrages d'Hugues dit d'Hancarville ${ }^{73}$ projettent au cours des années 1770 dansl'imaginaire dela France pré-révolutionnaire.

Il y aurait évidemment beaucoup à commenter sur le détournement de la 'fable' antique dans la peinture d'histoire au XVIIIe siècle. Disons seulement quelques mots d'un sujet moins connu qui est le portrait libertin. Il s'agit d'une tradition française remontant, pour le moins, à la seconde Ecole de Fontainebleau. On peut la définir comme une allégorisation réaliste, où le personnage représenté porte des attributs symboliques dont le décryptage échappe souvent à l'oeil moderne. Le premier degré est rarement le fait de ces oeuvres. C'est ainsi que le thème du Bon Pasteur ou de saint Jean-Baptiste, apparemment très orthodoxe ${ }^{74}$, sert à connoter chezl'homme un libertinage sexuel hétérodoxe. Le détournement desens se signale par des éléments incohérents par rapport à l'iconographie traditionnelle: une perruque ${ }^{75}$ ou un livre ${ }^{76}$ portés par saint Jean Baptiste. Vont dans le même sens les portraits 'à la romaine,' où le sujet apparaît les cheveux coupés courts, sans perruque et dans un costume de fantaisie proche de celui dont nous parlerons plus loin à propos des pèlerins d'amour: il existe deux curieux autoportraits parallèles de Claude Gillot et $\mathrm{d}^{\prime}$ Antoine Watteau conformes à ce modèle.

Pour ce qui est du libertinage hétérosexuel proclamé, la variété est plus grande encore, surtout si l'on y tient compte de l'art de la miniature, 
susceptible d'un collectionnisme discret. Certaines vulgates symboliques se rencontrent pendant tout le XVIIIe siècle. La pointe des seins découverte signale, en général, une dame professionnellement légère, ${ }^{77}$ mais certaines autres se satisfont de l'équivoque. ${ }^{78}$ Le détournement du religieux, dont la vertu blasphématoire va assez bien avec le 'libertinage spirituel,' est marqué assez lourdement dans la manière de traiter ces sujets. ${ }^{79}$ Mlle de Charolais se laisse peindre en habit de cordelier par allusion à la fonction mythique du 'cordon de saint François,' outil par excellence de toute une littérature pornographique anti-religieuse. La jeune princesse libertine, 'Frère Ange de Charolais,' faisait don de son portrait, peint ou réduit en miniature, à ses amants, dont le comte de Sade ${ }^{80}$ Son fils, le marquis, conserva dans son château de La Coste l'une de ces figurations fort peu dévotes. ${ }^{81}$

Mais la représentation la plus classique dans la première moitié du XVIIIle siècle reste celle des pèlerins $d$ 'amour qui parodient les pèlerins de Saint-Jacques de Compostelle ${ }^{82}$ par la coquille Saint-Jacques brodée sur chapeaux et mantelets et par le bâton surmonté du bourdon. La symbolique sexuelle de la coquille concave et du bourdon gonflé n'est pas le moins du monde équivoque. Ces pèlerins peuplent les tableaux de Watteau et de ses contemporains amis ou émules qui font comme lui voyager à Cythère. ${ }^{83}$ Les portraits de fantaisie à l'espagnole, que l'on retrouvera encore près d'un demi-siècle plus tard dans les 'figures' de Fragonard, connurent dès le début du siècle un succès européen. ${ }^{84}$ L'espagnolette $^{85}$ et le jeune éphèbe à collerette ${ }^{86}$ renvoient à un libertinage convenable, de bonne compagnie, ce qu'est souvent le pèlerin d'amour ou le berger de Cour quand il est traité avec grâce, comme dans le magnifique portrait du président de Gueydan peint par Rigaud (Aix-en-Provence, Musée Granet).

Les premiers spécialistes français du genre-Jean-Baptiste Santerre, Jean Raoux ou Alexis Grimou-firent des disciples dans les provinces et à l'étranger. Cela donne souvent des tableaux de dessus-de-porte à la médiocrité sans illusion qui inspirent eux-mêmes les arts décoratifs (porcelaine, ${ }^{87}$ argenterie, etc.). A Berlin, Antoine Pesne, conseillé par Frédéric II, prince passionné de cet art français qui déplaisait tant à son père, le roi-sergent, s'exerce à des travaux de portraitiste se souvenant de ce qu'il avait appris en France. A côté de jolies aristocrates interchangeables avec leur minois rond et inexpressif, Pesne peint des actrices dont il dévoile les charmes en bon commis-voyageur du libertinage. ${ }^{88}$ Pour le palais de Sanssouci et le divertissement d'un monarque dont le scepticisme allait largement au-delà de la religion, il représente un couple singulier, son ami le comte Gotter et sa nièce, qui combinent, en famille, les deux symboliques libertines: pèlerinage d'amour et décolleté généreux. ${ }^{89}$ On n'ose imaginer ce que cela signifie. 
Il est vrai aussi que presque toute la peinture française du XVIIIe siècle baigne dans une érotisation implicite du sujet: peinture $d^{\prime}$ 'histoire, scènes de genre, portraits, voire natures mortes sont susceptibles de ces déviations où l'air du temps et le goût des collectionneurs se marquent. Peignant pour l'aristocratie et la nouvelle classe financière, les artistes les mieux doués, membres de l'Académie de Peinture, sont certainement plus sensibles que d'autres à cette pression du marché. Il semble, par exemple, que les peintres de l'Académie de Saint-Luc, dont la clientèle est bourgeoise ou ecclésiastique, maintiennent une tradition de conformisme moral dans des oeuvres qui n'ornent jamais les hôtels des parvenus et de leurs émules de l'ancienne noblesse. Cela explique que cet art de peindre, caractéristique d'une société d'ordres et de droits de naissance qui est par-là même assez indifférente au jugement social, disparaisse avec la Révolution.

Ce n'est pas qu'une certaine veine libertine, sinon pornographique, ne le remplace, expression des nouvelles classes bourgeoises au pouvoir dont la présence se vérifie tout au long du XIXe siècle, mais la peinture de cabinet n'y a guère de part. C'est surtout dans l'illustration du livre, ces 'curiosa' à la portée de tout le monde, avec un Félicien Rops par exemple, que se poursuit la mise en images de l'idéologie libertine maintenant teintée d'anarchisme anti-bourgeois. Les musées du XIXe siècle reléguèrent dans leurs réserves les oeuvres du siècle passé qui avaient échappé aux destructions légitimées par la morale révolutionnaire ${ }^{90}$ et dont certaines ne sont connues que par le dessin ou la gravure. Cet art n'est pas encore totalement sorti de l'Enfer des Lumières.

\section{FRANÇOIS MOUREAU}

Université de Paris-Sorbonne

\section{Notes}

1 Voir l'Introduction de Marc Fumaroli au catalogue de l'exposition, La Peinture française du XVIIe siècle dans les collections américaines (Paris, New York, Chicago, 1982).

2 Nicolas Boileau-Despréaux, Satire $X$, vers 141.

3 Bernard Teyssèdre, L'Histoire de l'art vue du Grand Siècle. Paris, Julliard, 1964.

4 Nicolas Boileau-Despréaux, L'Art poétique, Chant III, vers 1-2.

5 Ouvrage diffusé par les gravures de Sébastien Le Clerc, Caractères des passions (1692). 
6 C. Henze, Lukas der Muttergottesmaler. Louvain, 1948, et cat. expo. Dijon, 1982-1983, La Peinture dans la peinture, 64-67.

7 Sur la Sainte Face, voir André Chastel, 'La Véronique', Revue de l'Art, n 40-41, 1978, 71-82, et le cat. expo. Dijon, op. cit., 62.

8 Michel Faré, Le Grand Siècle de la nature morte en France: le XVIIe siècle. Fribourg, Office du Livre, 1974; Michel et Fabrice Faré, La Vie silencieuse en France; la Nature morte au XVIIle siècle. Fribourg, Office du Livre, 1976.

9 'Je trouve dans un Panier de fraises de Chardin, par exemple, le recueillement d'une aussi pesante charge d'âme que dans son Bénédicité' (Andre Gide, 'Quelques réflexions sur l'abandon du sujet dans les arts plastiques,' Verves no1 [décembre 1937], 10).

10 Edith Greindl, Les Peintres flamands de nature morte au XVIIe siècle. Sterrebeek, Michel Lefebvre, 1983.

11 L'académie masculine était devenue obligatoire depuis 1666 pour les élèves français séjournant à Rome. Dans l'Encyclopédie, où le dessinateur Charles-Nicolas Cochin fut chargé en 1763 de la planche des 'Trois phases de l'apprentissage du dessin', on voit sur la droite 'des élèves qui dessinent d'après nature' (Explication des planches), et Cochin fournit en guise d'exemple deux académies de femmes gravées par De Fehrt et Prévost (Recueil des planches sur les Sciences, les Arts libéraux et les Arts mécaniques avec leur Explication, t. III, 1763, Seconde Livraison, seconde partie, pl. I, XX et XXI).

12 De l'Abus des nudités de gorge. Bruxelles, Foppens, 1675.

13 Cat. expo. Versailles, Charles Le Brun 1619-1690 peintre et dessinateur, 1963, n. 62-65.

14 'Watteau dans son temps', cat. expo. Washington-Paris-Berlin, 1984-1985 (version française, 473-77) et 'Watteau libertin?', Antoine Watteau (1684-1721), le peintre, son temps et sa légende, F. Moureau et M. Morgan-Grasselli éd. Paris-Genève, Champion-Slatkine, 1987, 17-22.

15 Krzysztof Pomian, Collectionneurs, amateurs et curieux. Paris, Venise: XVI-XVIIIe siècle. Paris, Gallimard, 1987.

16 Dans les guides de Paris, on en rencontre, dès la fin du XVIIe siècle, la liste, fort utile aux voyageurs qui les visitent (Le Livre commode des adresses de Paris par Abraham du Pradel [Nicolas de Blégny], éd. Edouard Fournier. Paris, Daffis, 1878, t. I, 236: 'Fameux curieux des ouvrages magnifiques' et 'Dames curieuses') ou les récits d'étrangers (Martin Lister, A Journey to Paris in the Year 1698. London, Jacob Tonson, 1699).

17 Voir le portrait de quelques 'curieux' dans le chapitre 'De la mode' des Caractères (éd. R. Garapon. Paris, Garnier, 1962, 392).

18 Leur goût se distingue nettement de celui de la vieille bourgeoisie qui est portée vers la peinture religieuse et les sujets flamands (scènes d'intérieur, de tavernes, etc.), ces 'magots', qui scandalisaient Louis XIV (Georges Wildenstein, 'Le goût pour la peinture dans le cercle de la bourgeoisie parisienne vers 1700 ', Gazette des Beaux-Arts, t. XLVIII, septembre 1956, 113-95).

19 François Moureau, 'Pierrot vainqueur d'Apollon: la seconde Querelle dans l'art de Watteau', D'un Siècle à l'autre: Anciens et Modernes; [Marseille], s.n., [1987] (XVIe Colloque du C.M.R. 17), 129-37.

20 François Moureau et Alain-Marc Rieu éd., Eros philosophe. Discours libertins des Lumières. Paris, Honoré Champion, 1984, et notre article: 'Watteau libertin?' cité à la n. 14. 
21 Margret Stuffmann, 'Les tableaux de la collection de Pierre Crozat', Gazette des Beaux-Arts, juillet-septembre 1968.

22 Il acquit La Mariée de village (Camesasca-Rosenberg 63), aujourd'hui au Palais de Charlottenbourg à Berlin.

23 Poème sur la galerie de M. de Jullienne (1764), manuscrit de dédicace du chevalier de Seré (Paris, Bibliothèque d'Art et d'Archéologie, ms. 103).

24 Claire-Eliane Engel, 'Le Régent collectionneur', La Régence. Paris, Armand Colin, 1970, 67: Les Singes peintres (perdu) et Le Bal champêtre (C.-R. 92). Voir aussi Arnaud Brejon de Lavergnée, 'Le Régent amateur d'art moderne', Revue de l'Art, no 62, 1983, 45 et sv., et Louis-François Dubois de Saint-Gelais, Description des tableaux du Palais-Royal avec la Vie des peintres à la tête de leurs ouvrages. Paris, 1727, 75-77.

25 Hugh M. Davidson, 'Fontenelle, Perrault and the Realignment of Arts', Literature and History in the Age of Ideas (Mélanges George Havens). Columbus, Ohio State University Press, 1975, 3-13.

26 Toile attribuée à Nicolas de Largillierre et connue sous le titre de Portrait allégorique dit: Le Régent en Dieu Pan (Louvre, inv. R. F. 2155). De fait, la peau de chevreau qui l'habille est emblématique de Bacchus, le dieu-chevreau.

27 En ce début du XVIIIle siècle, la représentation de Bacchus témoigne d'une philosophie naturaliste (Robert Tomlinson, La Fête galante: Watteau et Marivaux. Genève-Paris, Droz, 1981, ch. III: 'Bacchus ou la Nature,' 75-90).

28 Bacchus: Fête bachique (C.-R. 47 A); Les Enfants de Bacchus (C.-R. 74); Le Bosquet de Bacchus (C.-R. 141). Momus: L'Amour au théâtre français (C.-R. 187). Pan: L'Amour mal accompagné (C.-R. 75); Voulez-vous triompher des belles? (C.-R. 152). Silène: Les Enfants de Silène (C.-R. 73); Arlequin, Pierrot et Scapin (C.-R.155); Vénus: Le Pèlerinage à l'île de Cythère (C.-R. 168).

29 Robert Tomlinson, La Fête galante: Watteau et Marivaux; op. cit.

30 Christian Michel, 'Les Fêtes galantes: peintures de genre ou peintures d'histoire?', Antoine Watteau (1685-1721), op. cit., 111-12.

31 Astrée, 'ode à S.A.R. Mgr le duc d'Orléans', etc. L'ode La Peinture du même Houdar de la Motte exprime une conception très moderne de l'art pour l'art dégagée des contingences de la représentation du réel.

32 'Libertin d'esprit, mais sage de moeurs': Edme-François Gersaint, 'Abrégé de la vie d'Antoine Watteau' (1744) (Vies anciennes de Watteau, Pierre Rosenberg éd., Paris, Hermann, 1984, 38). Voir notre: 'Watteau libertin?', Antoine Watteau (1684-1721), op. cit., 17.

33 Très nombreux dessins, dont certains ont été gravés. Par exemple, Les Bacchanales ou La Vie des Satyres (Bernard Populus, Claude Gillot (1673-1722). Catalogue de l'Ctuvre gravé. Paris, Maurice Rousseau, 1930, no 1-8).

34 Bacchanale (Posnan, Musée national); Le Vin réchauffe l'amour ou Pèlerinage d'amour à Silène (toile, $46 \times 35 \mathrm{~cm}$ ) (Paris, coll. de l'auteur): le pèlerin d'amour à droite correspond à un dessin connu de Watteau (Louvre, Département des Arts graphiques, cat. Parker-Mathey 104).

35 Voir nos références dans 'Pierrot vainqueur d'Apollon', loc. cit., 136, n. 31.

36 Le Voyage du Parnasse. Rotterdam, Fritsch et Böhm, 1716, 165-66. Les citations précédentes sont tirées de la même visite que font Crantor et son disciple Cliton, tous deux partisans des 'Anciens,' chez le financier 'moderne' et collectionneur, Nasidiène. 
37 Michael Fried a étudié ce phénomène avec finesse (La Place du spectateur.

Esthétique et origines de la peinture moderne. Paris, Gallimard, 1990, ch. II; trad. de Painting and Beholder in the Age of Diderot. Chicago, Chicago UP, 1988).

38 Erotica and the Enlightenment. Peter Wagner ed. Frankfurt/M, Bern, New York, Paris, Peter Lang, 1990, n'étudie que la gravure, art de diffusion et d'allusion, pratique socialisée, alors que la peinture s'adresse à un destinataire unique, le voyeur-amateur, qui peut exiger la 'singularité.'

39 Ces Livres qu'on ne lit que d'une main. Lecture et lecteurs de livres pornographiques au XVIIIe siècle. Aix-en-Provence, Alinéa, 1991.

40 [François Génard], L'Ecole de l'Homme. Nouvelle édition. 'Londres' [Paris], 1753, t. I, 114. Sur la naissance des 'cabinets', voir l'ouvrage récent d'André Mérot, Retraites mondaines. Aspects de la décoration intérieure à Paris au XVIIe siècle. Paris, Le Promeneur, 1990.

41 Notice du Mercure, juillet 1721 (Vies anciennes, op. cit., 7).

42 Anne-Claude-Philippe, comte de Caylus, 'La vie d'Antoine Watteau' (1748) (Vies anciennes, op. cit., 72).

43 Ibid., 85. Dans une variante supprimée, Caylus suggère que Watteau, qui l'avait chargé de cette mission, le soupçonnait de n'en avoir rien fait.

44 A de très rares exceptions près, rappelons que le titres des tableaux de Watteau viennent de Jean de Jullienne qui les fit graver après la mort de l'artiste.

45 Caylus, op. cit., 68.

46 Helmut Börsch-Supan, Der Maler Antoine Pesne, Franzose und Preusse. [Friedberg/H], Podzun-Pallas, [1986], no 76 (Berckenhagen 497).

47 Les dessins de nus partirent, pour certains (contre-épreuves), vers la Suède avec le comte Carl-Gustav Tessin. Diane au bain était en Angleterre avant 1737 dans la collection de Sir Thomas Seabnight. Nymphe et Satyre (Paris, Louvre. C.-R. 104) semble avoir été peint pour le duc d'Arenberg, prince au service de l'Empire. La Toilette intime appartenait en 1724 au comte de Hoym, célèbre bibliophile et collectionneur, ambassadeur de Saxe à Paris. La Toilette apparaît à la vente du prince de Conti en 1777.

48 Voir n. 28.

49 La Signature du contrat (C.-R. 62); Fête galante près de la fontaine de Neptune (C.-R. 94); Récréation italienne (C.-R. 129); Leçon d'amour (C.-R. 153); Les Champs-Elysées (C.-R. 156); Fêtes vénitiennes (C.-R. 180); Divertissements champêtres (C.-R. 183).

50 Voir notre 'Watteau dans son temps' (n. 14) et 'Pierrot vainqueur d'Apollon' ( $n$. 19).

51 Alain-Marie Bassy, La Fables de La Fontaine. Quatre siècles d'illustration. Paris, Promodis, 1986. Peintre animalier, Jean-Baptiste Oudry en fut le meilleur interprète: recueil de 276 dessins récemment démembré.

52 Contes et nouvelles en vers. Amsterdam [Paris], 1762, 2 vol., ' 144 morceaux de gravure.' Voir Henry Cohen, Guide de l'amateur de livres à figures et à vignettes du XVIIIe siècle; 3e éd. Paris, Rouquette, 1876, col. 232-36.

53 Gisela Zick, 'Les Oies de frère Philippe', Keramos, 72, mai 1976, 17-28.

54 Sur ces différents tableaux, voir la notice de l'oeuvre de Boucher, dans cat. expo. Paris, 1986-1987, François Boucher 1703-1770, no 7. 
55 Bernard Hercenberg, Nicolas Vleughels, peintre et directeur de l'Académie de France à Rome 1668-1737. Paris, Laget, 1975, no 113: Le Gascon puni, 1729 (Contes, 2e partie); no 122: Le petit chien qui secoue de l'argent et des pierreries, 1732 (C., 3e partie); no 132-33 (vers 1735): Le Bât (C., 3e Partie); no 134-35: La Jument du compère Pierre (Nouveaux Contes, 1674); no 136: Le Villageois qui cherche son veau (C., 2e Partie); no 137: Frère Luce (L'Ermite: C., 2e Partie).

56 'Subleyras illustrateur des Contes de La Fontaine', cat. expo. Paris, 1987, Subleyras 1699-1749, 173-95: n 18: L'Ermite; $\mathrm{n}$ 23: Les Oies de frère Philippe; n 26: Le Faucon (C., 3e Partie); no 28: La Courtisane amoureuse (C., 3e Partie); no 30: Le Bât; no 31 La Jument du compère Pierre.

57 Cat. expo. Paris, Boucher, op. cit., no 48, 221. Diderot connaissait ces tableaux qu'il croyait être le portrait de la propre femme de Boucher. Le philosophe du: 'mes pensées, ce sont mes catins' a parlé bien sévèrement d'un 'Boucher qui n'avait pas rougi de prostituer lui-même sa femme' (Salon de 1767). C'était en faire à bon compte un autre Jean-François Rameau.

58 Cat. expo. Paris, 1987-1988, Fragonard. Paris, Réunion des Musées nationaux, no 125-141, 255-92.

59 'Que voulez-vous que cet artiste jette sur la toile? Ce qu'il a dans l'imagination. Et que peut avoir dans l'imagination un homme qui passe sa vie avec les prostituées du plus bas étage?' écrit-il du Premier peintre du Roi (Salon de 1765).

60 Voir aussi La Chaise basculée (Paris, coll. part.) (cat. expo., Fragonard, no 216): trois adolescents et une jeune fille dans une position délicate.

61 Le chien est humanisé, dressé, 'fait homme': L'Education fait tout (Sao Paulo, Museu de Arte); Portrait d'une femme tenant un chien (New York, Metropolitan Museum) (W.-M. 273). Sur la valeur érotique du chien chez Watteau, voir Gérard Le Coat, 'Watteau et l'imaginaire social: la représentation animale comme étude de cas', Antoine Watteau (1684-1721), op. cit., 181-84.

62 Jeune fille tenant dans ses bras un chat et un chien (Tel Aviv, coll. part., W.-M. 435); Le Chat emmailloté (Grasse, Musée Fragonard: eau-forte; tableau perdu); Garçonnet au chat (Louvre, Département des Arts graphiques, R.F. 40959).

63 Jeune fille tenant dans ses bras une colombe (Tel Aviv, coll. part.; W.-M. 436).

64 La Jeune fille à la marmotte (Moscou, Musée Pouchkine).

65 La Chemise enlevée (Paris, Louvre).

66 Il existe de nombreuses versions de La Gimblette qui prouvent le succès du sujet (cat. expo., Fragonard, no 110); Les Pétards (Boston, Museum of Fine Arts: dessin gravé); Les Jets d'eau (Williamstown, S. and F. Clarke Art Institute: dessin gravé); Le Feu aux poudres (brandon allumé) (Paris, Louvre); Le Verre d'eau (gravé en 1788 par Nicolas Ponce; W. 285); La Marchande de boudin (Vienne, Albertina: dessin).

67 A titre d'exemple: Chardin, Une Femme occupée à cacheter une lettre (Berlin, Stiftung Preussischer Kulturbesitz): serviteur allumant une bougie que fixe la dame; $L a$ Serinette (Paris, coll; part.): oiseau en cage et instrument de musique de substitution pour la dame. Greuze, Une jeune fille, qui pleure son oiseau mort (Salon de 1765) (Edimbourg, National Galleries of Scotland): Diderot y voit une belle idylle' à la manière de Gessner. Pourtant les éléments de la symbolique sexuelle y sont présents (cage ouverte et oiseau mort).

68 Dessin gravé en 1778 par Fragonard lui-même (G.Wildenstein, Fragonard aquafortiste. Paris, 1956, no XXIII).

69 'Rome 1756-1761', cat. expo., Fragonard, op.cit., ch. II, 61-70. 
70 Par exemple, ses chapitres sur la différentiation sexuelle dans l'art antique: Johann Winckelmann, Histoire de l'art de l'Antiquité (trad. Michel Huber). Leipzig, l'auteur et J.G.I. Breitkopf, 1781, 3 vol; in-4: Livre Ier, ch. I: 'L'indication du sexe'(VIII-B). Art grec: livre IV, ch. II: 'Du dessin du nu fondé sur la beauté' (I-B); satyres , Silène, Pan, Bacchus (II-A); Vénus (IV-A); ch. III: 'De l'expression de la bienséance' (satyres, etc.) (I-C); ch. IV: 'De la beauté des superficies du corps' ('poitrine des hommes', 'sein des femmes', 'partie inférieure du corps'(III), etc.

71 On pense au 'ballet' obscène connu sous le titre de L'Art de $F^{* * *}, 1747$ (Arsenal: Rés. 8 B.L. 35550); voir Miguel Benitez, 'Philosophes et libertins: le cas Durey de Morsan', Eros philosophe, op. cit., 22-25.

72 G. Wildenstein, Fragonard aquafortiste, op. cit., no III-VI.

73 Monuments de la vie privée des douze Césars. Caprées [Nancy] , Sabellus, 1780. Monuments du culte secret des dames romaines. Caprées [Nancy], Sabellus, 1784: au total cent gravures et deux frontispices de style spinthrien. Veneres uti observantur in gemmis antiquis. Lugduni Batavorum [Naples, c. 1771]: 2 frontispices et 68 planches.

74 Voir notre 'Watteau libertin?', loc. cit.

75 Miniature sur ivoire, début du XVIIIe siècle (Paris, coll. de l'auteur).

76 Miniature dite de Molière tenant le texte de Dom Juan à la main, gouache sur velin, XVIIe siècle (Pézenas, Musée Vulliod-Saint-Germain).

77 Nombreuses miniatures. Portrait annoté au dos: 'Jeanne Marie Gentil, née à Troyes 28 Xbre 1733, morte célibataire à Dampierre (Aube)'. Pierre-Jean Grosley en parle avec une émotion reconnaissante dans sa Vie, Londres et Paris, Barrois,1787, 96: miniature sur ivoire signée 'G. G. s...p' (Paris, coll. de l'auteur).

78 Les actrices surtout, comme La Trompettina, plantureuse cantatrice et courtisane vénitienne peinte par Antoine Pesne vers 1708 (Berlin, Charlottenbourg) (Berckenhagen 306 a).

79 Il existe évidemment une pratique au premier degré du portrait en vêtement de nonne, telle la jolie et paternelle image que Pesne donne de sa fille Hélène, religeuse cistercienne (Berlin, Charlottenbourg) (Berckenhagen 246 a); des dames de la bonne société se font peindre en habit monastique ou en sainte par humilité dévote: portrait de la reine Marie Leszczinska par Jean-Baptiste Santerre; Mme de Villars en sainte Geneviève (gravure de J. N. Tardieu). Mais, outre les travaux d'aiguille, on se divertissait dans les couvents à peindre des miniatures représentant malicieusement des scènes fantasmatiques: religieuse fumant la pipe et dégustant un verre de vin (velin, XVIIIe siècle; coll. de l'auteur).

80 Maurice Lever, Donatien Alphonse François, marquis de Sade, Paris, Fayard, 1991, 29-33 et n. 10, reproduction en h.-t. d'une toile attribuée à Nattier. Diverses miniatures: Chantilly, Musée Condé et coll. Xavier de Sade, Maurice Lever, François Moureau.

81 François Champarnaud, 'La galerie du marquis de Sade au château de La Coste', Dix-Huitième Siècle, no 21, 1989, 445-47, reproduction en hors-texte du tableau du Musée de Versailles donné à Charles-Joseph Natoire depuis la découverte d'un dessin préparatoire au Musée de Darmstadt.

82 Pèlerins et chemins de Saint-Jacques de Compostelle. Paris, Archives nationales, 1965.

83 F. Moureau, 'Les chemins de Cythère', cat. expo., Watteau, op. cit., 495-503. Watteau et sa génération. Paris, Galerie Cailleux, 1968. 
84 Ils apparaissent chez Frans Hals et chez Rembrandt, puis en France, au début du XVIIIe siècle, chez Alexis Grimou, protégé de la très libertine comtesse de Verrue, qui copie les sujets de Rembrandt, et chez Jean-Baptiste Santerre et Jean Raoux. Watteau en reprend le costume (La Finette, L'Indifférent, etc.). Charles-Antoine Coypel et Charles-Joseph Natoire qui illustrent Don Quichotte popularisent cette image avant que Carle Vanloo n'en donne une interprétation affadie (La Lecture espagnole. Saint-Pétersbourg, Ermitage).

85 François Moureau, 'Iconographie théâtrale': l'espagnolette, cat. expo., Watteau, op. cit., 522-23.

86 Parmi de multiples exemples, Le Jeune Pèlerin d'Alexis Grimou (Bordeaux, Musée des Beaux-Arts).

87 A Meissen (Harald Marx, 'Watteau de seconde main. De l'expansion du 'goût à la Watteau' dans la Saxe du milieu du XVIIIe siècle', Antoine Watteau, (1684-1721), op. cit., 291-300), ou à Munich dans la manufacture de Nymphenbourg (Rainer Rückert, Franz Anton Bustelli, Munich, Hirmer, 1963, fig, 14: 'Der stürmische Galan').

88 Voir la n. 78.

89 Le comte Gustave Adolphe Gotter et sa nièce Frédérique von Wangenheim en habits de pèlerins (Postdam, Sanssouci) (Berckenhagen $132 \mathrm{e}$ ).

90 En 1860, le docteur La Caze acheta pour 'un louis' (20 F or) La Chemise enlevée de Fragonard 'exposée sur un trottoir' (E. et J. de Goncourt, Fragonard, Paris, 1865, 276): le tableau est aujourd'hui au Louvre. 